\title{
Pathophysiological Remodeling of Mouse Cardiac Myocytes Expressing Dominant Negative Mutant of Neuron Restrictive Silencing Factor
}

\author{
Makoto Takano; Hideyuki Kinoshita; Takao Shioya; Masayuki Itoh; \\ Kazuwa Nakao; Koichiro Kuwahara
}

\begin{abstract}
Background: It has been previously reported that the transgenic mouse expressing the dominant negative mutant of the neuron restrictive silencing factor (dnNRSF) in the heart died from lethal arrhythmia, so the present study aimed to clarify the electrophysiological alteration of the ventricular myocyte isolated from the dnNRSF mouse.

Methods and Results: The action potential (AP) and membrane currents were recorded using the whole-cell patch-clamp method. Intracellular $\mathrm{Ca}^{2+}$ was measured with Indo-1AM. The AP of dnNRSF myocytes exhibited reduction of resting membrane potential, prolongation of AP duration, and frequent early afterdepolarization (EAD). The EAD was completely inhibited by SEA0400, a specific blocker of the $\mathrm{Na}^{+-} \mathrm{Ca}^{2+}$ exchanger (NCX). The most notable alteration of membrane current was a reduction in the inward rectifier $\mathrm{K}^{+}$current (IK1) density. In addition to re-expression of fetal type cardiac ion channels, a $\mathrm{Na}^{+}$-permeable, late inward current was observed in a small population of dnNRSF myocytes. The diastolic intracellular $\mathrm{Ca}^{2+}$ concentration was also raised in dnNRSF myocytes, and spontaneous $\mathrm{Ca}^{2+}$ oscillation was induced by $\beta$-adrenergic stimulation.
\end{abstract}

Conclusions: In dnNRSF myocytes, the "repolarization reserve" of the AP was significantly reduced by specific alterations in membrane currents. Under these conditions, the amplitude of EAD generated by the inward NCX current might be enlarged, thereby increasing the cells' vulnerability to ventricular arrhythmia. (Circ J 2010; 74: 2712-2719)

Key Words: Arrhythmia; Cardiac myocytes; Hypertrophy; REST/NRSF

V entricular arrhythmias are a major cause of sudden death in patients with heart failure or cardiac hypertrophy. A characteristic genetic alteration in heart failure appears to be reactivation of fetal cardiac genes, such as atrial natriuretic peptide (ANP), $\alpha$-skeletal acin, $\beta$-myosin heavy chain, and ion channels, including the hyperpolarization-activated, cyclic nucleotide-gated cation channels (Ih; Hcn2; Hcn4) and T-type $\mathrm{Ca}^{2+}$ channels (Ica-T; Cacnalh). However, the mechanisms of lethal arrhythmias still remain unclear. ${ }^{1-4}$ We have previously reported that a transcriptional silencer, REST/NRSF (RE-1 silencing transcription factor/ neuron restrictive silencing factor) played an important role in transcriptional regulation of ANP and Hcn4 in vitro. ${ }^{5,6} \mathrm{In}$ accordance with this, the expressions of ANP, Hcn2, Hcn4, Cancna1h and transient receptor potential channel (Trpc1) were significantly increased in transgenic mice carrying the dominant negative mutant of REST/NRSF in their heart
(dnNRSF)..$^{7-9}$ The dnNRSF mice were vulnerable to ventricular arrhythmia, and started to die suddenly at approximately 8 weeks after birth without showing symptoms of pumping failure, and blockade of ICa-T by efonidipine rescued them from sudden death. ${ }^{7,10}$ In a previous study, we reported that the action potential (AP) waveform was significantly different between dnNRSF mice and their wild-type (WT) littermates. ${ }^{10}$ Because the ionic mechanisms underlying such alteration of the AP are not clear at present, in the present study we investigated the electrophysiological properties of single ventricular myocytes isolated from dnNRSF mice, aiming to get an insight of the cellular mechanism of arrhythmias.

\section{Methods}

All experiments were approved in advance by the Animal Ethics Committee of Jichi Medical University. The investi-

Received July 6, 2010; revised manuscript received August 4, 2010; accepted August 6, 2010; released online October 30, 2010 Time for primary review: 13 days

Department of Physiology, Jichi Medical University, Tochigi (M.T., M.I.); Department of Medicine and Clinical Sciences, Graduate School of Medicine, Kyoto University, Kyoto (H.K., K.N., K.K.); and Department of Physiology, Faculty of Medicine, Saga University, Saga (T.S.), Japan

Mailing address: Makoto Takano, Department of Physiology, Jichi Medical University, 3311-1 Yakushiji, Shimotsuke, Tochigi 329-0498, Japan. E-mail: takanom@jichi.ac.jp

ISSN-1346-9843 doi:10.1253/circj.CJ-10-0652

All rights are reserved to the Japanese Circulation Society. For permissions, please e-mail: cj@j-circ.or.jp 


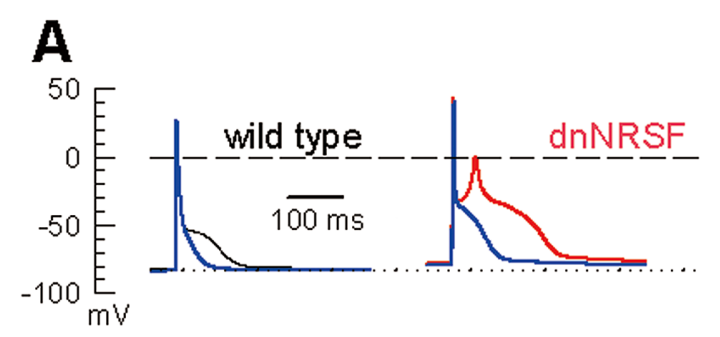

B

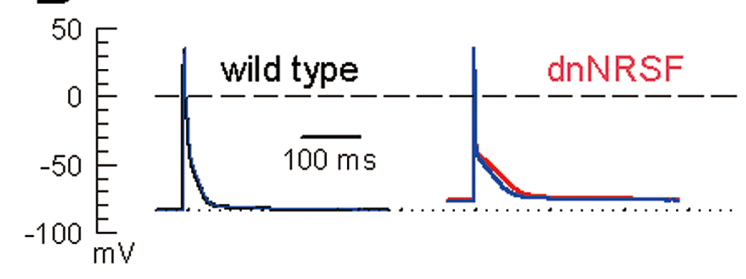

\section{C-a}

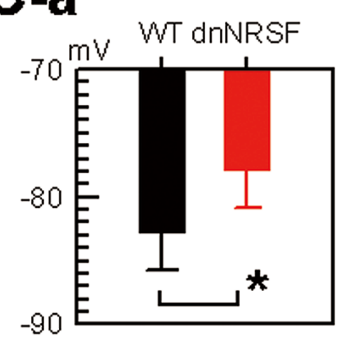

D-a

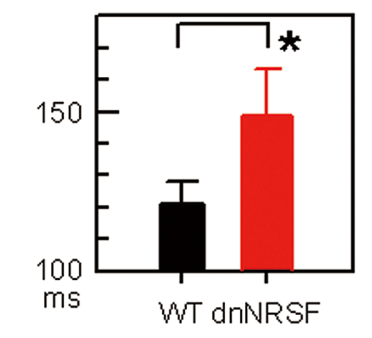

E-a

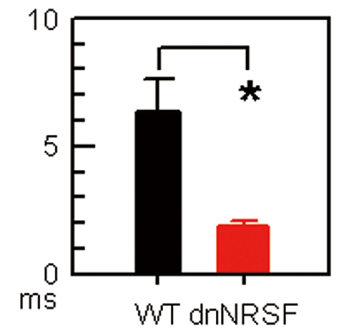

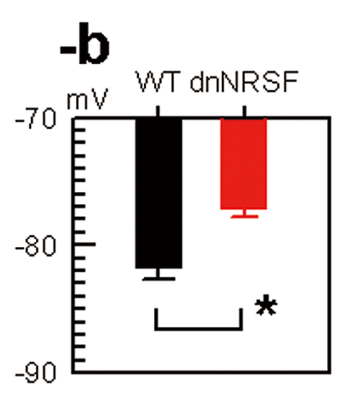

$-\mathbf{b}$

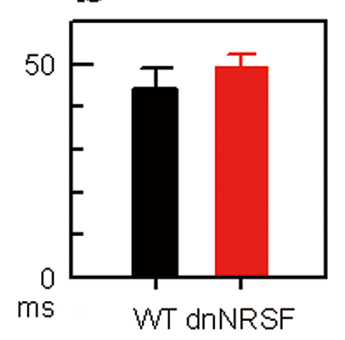

$-\mathbf{b}$

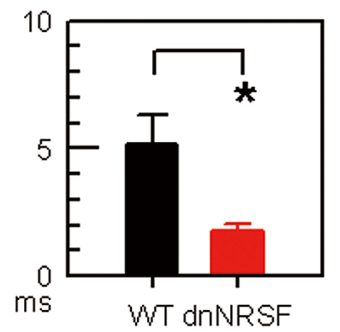

Figure 1. Action potential (AP) wave forms of ventricular myocytes isolated from wild-type (WT) and dnNRSF mice. (A) AP recorded using the perforated patch method. Black line, AP of WT; red line, AP of dnNRSF; blue line, APs recorded in the presence of $10 \mu \mathrm{mol} / \mathrm{L}$ SEA0400. The dashed line indicates $0 \mathrm{mV}$. For comparison, the resting membrane potential (RMP) of WT myocyte is shown by the dotted line. (B) AP recorded with the ruptured patch method. The pipette solution contained $5 \mathrm{mmol} / \mathrm{L}$ EGTA. The AP wave forms were almost superimposable in the presence (blue lines) and absence (WT, black line; dnNRSF, red line) of SEA0400. (C-a) Summary of RMP measured with the perforated patch method. RMP of WT was $-82.7 \pm 3.1 \mathrm{mV}(\mathrm{n}=15)$; RMP of dnNRSF was significantly depolarized $(-77.8 \pm 3.0 \mathrm{mV}, \mathrm{n}=15)(\mathrm{P}<0.05)$. (C-b) RMP measured with the ruptured patch method. RMP of WT, $-81.7 \pm 1.10 \mathrm{mV}(\mathrm{n}=15)$; RMP of dnNRSF, $77.1 \pm 0.8 \mathrm{mV}(\mathrm{n}=15)(P<0.05)(\mathrm{D}-\mathrm{a})$ Duration of 90\% AP (APD90) measured with the perforated patch method. APD9o of dnNRSF was significantly longer $(148.5 \pm 14.9 \mathrm{~ms}, \mathrm{n}=15)$ than that of WT $(120.8 \pm 7.0 \mathrm{~ms}, \mathrm{n}=15)(P<0.05)$. ( $\mathrm{D}-\mathbf{b})$ APDgo measured with the ruptured patch method. APD90 of dnNRSF is $49.7 \pm 2.8 \mathrm{~ms}$ $(n=15)$; APDgo of WT, $44.2 \pm 4.9 \mathrm{~ms}(n=15)$. No statistical difference. (E-a) Duration of the AP measured at 0 mV (APD@0 mV) with the perforated patch method. APD@OmV of dnNRSF was significantly shorter $(1.87 \pm 0.21 \mathrm{~ms}, \mathrm{n}=15)$ than that of WT $(6.35 \pm 1.25 \mathrm{~ms}, \mathrm{n}=15)(\mathrm{P}<0.05)$. ( $\mathrm{E}-\mathrm{b}) \mathrm{APD} @ 0 \mathrm{mV}$ measured with the ruptured patch method. dnNRSF, $1.74 \pm 0.32 \mathrm{~ms}(\mathrm{n}=15)$; WT, 5.16 $\pm 1.11 \mathrm{~ms}(n=15)(P<0.05)$. dnNRSF, dominant negative mutant of the neuron restrictive silencing factor.

gation conformed with the Guide for the Care and Use of Laboratory Animals published by the US National Institutes of Health (NIH Publication No. 85-23, revised 1996).

\section{Cell Isolation}

Ventricular myocytes of dnNRSF mice and their WT littermates (14-16 weeks, body weight $\sim 25 \mathrm{~g}$ ) were obtained by a method reported previously. ${ }^{11}$

\section{Composition of the Solutions}

For the perforated patch experiment, the pipette solution contained (mmol/L); 110 aspartic acid, $30 \mathrm{KCl}, 5 \mathrm{~K} 2 \mathrm{ATP}, 5$ $\mathrm{Na} 2$ creatine phosphate, $0.1 \mathrm{Na} 2 \mathrm{GTP}, 1 \mathrm{MgCl}_{2}, 10 \mathrm{HEPES}$ ( $\mathrm{pH}=7.2$ with $\mathrm{KOH}$ ). Amphotericin (stock solution; $30 \mathrm{mg} / \mathrm{ml}$ in DEMSO) was added to this solution (final concentration:
$0.3 \mathrm{mg} / \mathrm{ml}$ ). For the ruptured whole-cell patch experiments, the low-Ca ${ }^{2+}$ pipette solution contained: 110 aspartic acid, $30 \mathrm{KCl}, 5 \mathrm{~K}_{2} \mathrm{ATP}, 5 \mathrm{Na}_{2}$ creatine phosphate, $0.1 \mathrm{Na} 2 \mathrm{GTP}, 5$ EGTA, 5 HEPES ( $\mathrm{pH}=7.2$ with $\mathrm{KOH})$. To record the $\mathrm{Ca}^{2+}$ and $\mathrm{Na}^{+}$currents, the electrode was filled with $\mathrm{Cs}^{+}$-rich pipette solution containing: $100 \mathrm{CsCl}, 50 \mathrm{NMDG}, 5 \mathrm{MgATP}$, 10 EGTA, 5 HEPES ( $\mathrm{pH}=7.2$ with $\mathrm{CsOH}$ ). The physiological bathing solution contained; $140 \mathrm{NaCl}, 5.4 \mathrm{KCl}, 0.5 \mathrm{MgCl}_{2}$, $1.8 \mathrm{CaCl}_{2}$. To record $\mathrm{Na}^{+}$and $\mathrm{Ca}^{2+}$ currents, $\mathrm{KCl}$ was replaced with CsCl. SEA0400 (Taisho Pharmaceutical) was dissolved in DEMSO as a stock solution $(10 \mathrm{mmol} / \mathrm{L})$.

\section{Electrophysiology}

$\mathrm{AP}$ and membrane current were recorded using an Axopatch200B amplifier and Digidata 1320 interface (Axon, 


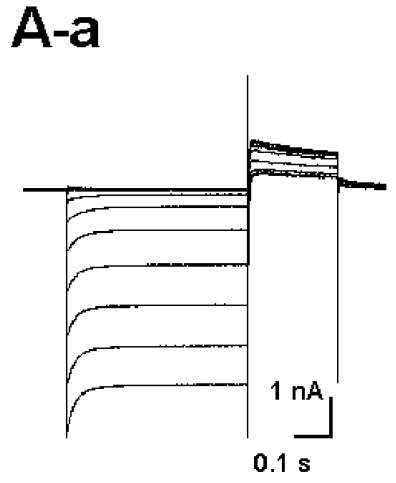

$-\mathbf{b}$

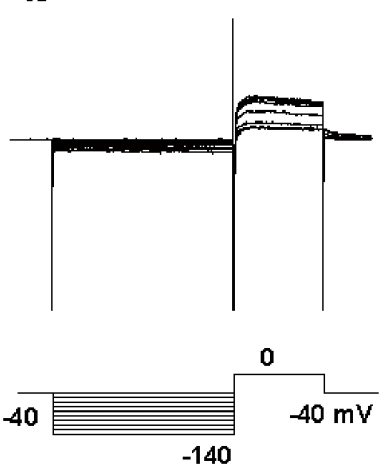

C
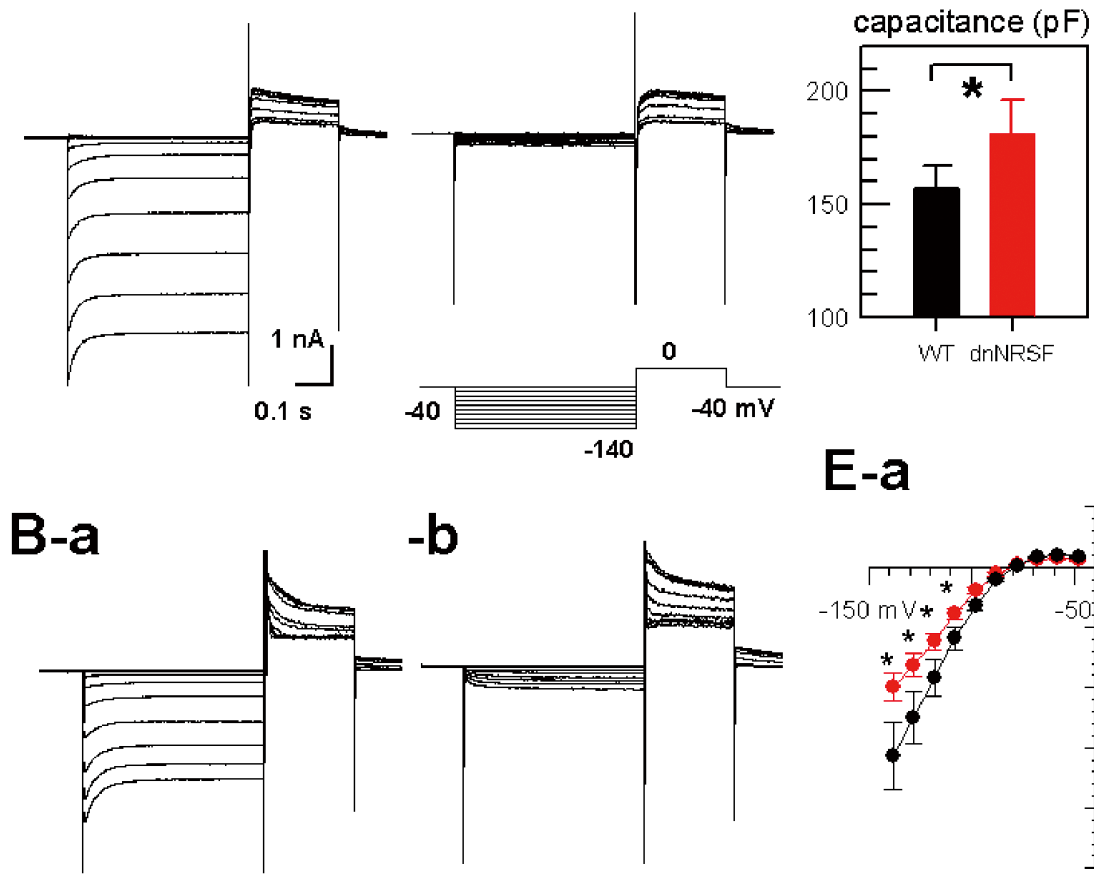

E-a

D

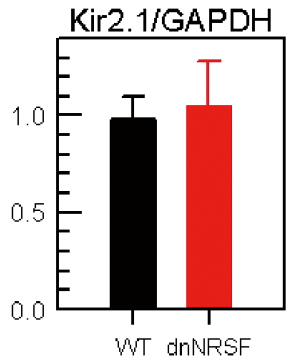

$-b$

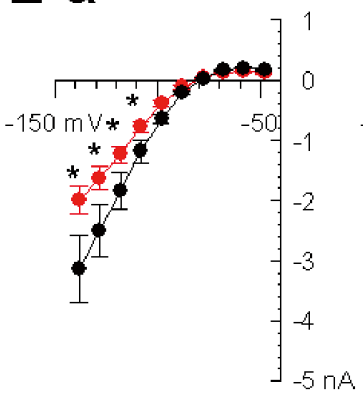

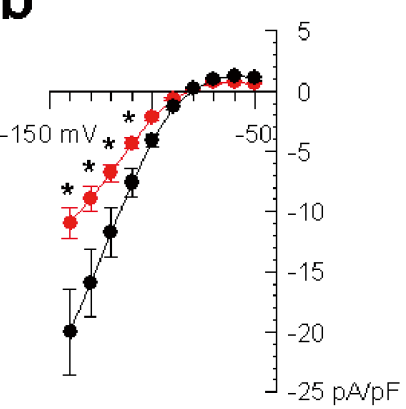

Figure 2. The reduction of $I_{k 1}$ density in dnNRSF myocytes. (A-a) The current traces of $I_{k 1}$ in a wild-type (WT) myocyte recorded in physiological bathing solution. (A-b) The family of current traces recorded in the presence of $1 \mathrm{mmol} / \mathrm{L} \mathrm{Ba}^{2+}$. The traces were recorded in the same myocyte as in (A-a). (B-a) Ik1 recorded in a dnNRSF myocyte. (B-b) In the same myocyte shown in (B-a), $1 \mathrm{mmol} / \mathrm{L} \mathrm{Ba}^{2+}$ completely inhibited $\mathrm{I}_{\mathrm{K} 1}$, and disclosed the presence of $\mathrm{l}$ current at membrane potentials more negative than $-80 \mathrm{mV}$. Note that the amplitude of the transient outward current at $0 \mathrm{mV}$ is larger in dnNRSF. (C) Membrane capacitance of dnNRSF myocyte $(181.1 \pm 15.3 p F, n=10)$ was significantly larger than that of a WT myocyte $(156.8 \pm 10.2 p F, n=10)(P<0.05)$. (D) qPCR for Kir2.1 mRNA. Ratios of Kir2.1/GAPDH are indicated and are not statistically different between WT and dnNRSF myocytes. (E-a) The amplitudes of $I_{k 1}$ in a WT myocyte (black) and dnNRSF myocyte (red). The amplitude was measured at the ends of hyperpolarizing pluses. *Statistical difference $(n=10, P<0.05)$. (E-b) The densities of Ik1 in a WT myocyte (black) and dnNRSF myocyte (red). *Statistical difference $(n=10, P<0.05)$. dnNRSF, dominant negative mutant of the neuron restrictive silencing factor; Ih, hyperpolarization-activated cation current; Ik1, inward rectifier $\mathrm{K}^{+}$current; qPCR, quantitative polymerase chain reaction.

CA, USA). The electrode resistance was $3-4 \mathrm{M} \Omega$. All the experiments were carried out at $33-35^{\circ} \mathrm{C}$.

\section{Imaging}

Myocytes were loaded with Indo1-AM $(10 \mu \mathrm{mol} / \mathrm{L}$ in the bathing solution) for $15 \mathrm{~min}$ at room temperature. Indo-1 was excited at 340-380 nm, and the fluorescent images were captured with a CCD camera. The intensity of fluorescence was measured at $405 \pm 20 \mathrm{~nm}\left(\mathrm{~F}_{405}\right)$ and $480 \pm 20 \mathrm{~nm}\left(\mathrm{~F}_{480}\right)$ using a beam-splitter and CCD camera (AquaCosmos Double View system, Hamamatsu photonics, Hamamatsu, Japan). Fluorescent images were continuously captured at the maximum rate available in our system ( 1 frame per $22 \mathrm{~ms}$ ).

\section{qPCR Analysis}

Total RNA was obtained using Trizol reagent following manufacture's instruction. Reverse transcriptase polymerase chain reaction (RT-PCR) was performed using Platinum PCR SuperMix (Invitrogen, San Diego, CA, USA). Quantitative real-time RT-PCR (qPCR) was conducted for Kir2.1 and GAPDH using predesigned TaqMan Gene Expression Assays (Applied Biosystems, Foster City, CA, USA). The reaction was performed on an ABI Prism 7700 System
(Applied Biosystems). The mRNA levels of Kir2.1 were normalized to the endogenous GAPDH.

\section{Statistical Analysis}

Data are shown as mean \pm SEM. Statistical difference was evaluated using Student's t-test. Differences were considered significant when $\mathrm{P}<0.05$.

\section{Results}

\section{AP Waveform of dnNRSF Cardiac Myocytes}

We first recorded the APs of single ventricular myocytes under the condition of intact intracellular $\mathrm{Ca}^{2+}$ transient, because it has been reported that the specific blocker of the $\mathrm{Na}^{+}-\mathrm{Ca}^{2+}$ exchanger (NCX), SEA0400, suppresses the plateau phase of the AP in the mouse ventricle. ${ }^{12}$ For this purpose, we used the perforated patch method. Figure 1A compares the AP waveform recorded in WT and dnNRSF myocytes; in the dnNRSF myocytes the resting membrane potential (RMP) was more depolarized, the AP duration (APD 90 ) was significantly prolonged, and early afterdepolarization (EAD) was observed in $37.3 \%$ (28 of 75 cells), as reported previously. ${ }^{10}$ As shown in Figure 1A, SEA0400 
shortened the plateau phase in both WT and dnNRSF myocytes. Furthermore, SEA0400 completely suppressed EADs in dnNRSF myocytes. A similar effect has been reported in dogs. ${ }^{13}$ In contrast, when the AP was recorded using the ruptured patch method with low-Ca ${ }^{2+}$ pipette solution, the waveforms were almost superimposable in the presence and absence of SEA0400 (Figure 1B), presumably because the activity of the NCX was almost completely suppressed by chelating intracellular $\mathrm{Ca}^{2+}$. Most notably, the RMP of dnNRSF myocytes was significantly more depolarized than that of WT myocytes, irrespective of the experimental conditions (Figure 1C). As summarized in Figure 1D, APD90 was significantly prolonged in the perforated patch experiments, whereas in the ruptured whole-cell patch experiments, APD 90 was not statistically different between WT and dnNRSF myocytes. However, the rate of repolarization at $-60 \mathrm{mV}$ was significantly slower in dnNRSF myocyte, even in these experimental conditions $(1.05 \pm 0.11 \mathrm{~V} / \mathrm{s}$ in WT $(\mathrm{n}=15) ; 0.62 \pm 0.08 \mathrm{~V} / \mathrm{s}$ in dnNRSF $(\mathrm{n}=15) ; \mathrm{P}<0.05)$. The APD measured at $0 \mathrm{mV}$ (APD@0mV) was, however, significantly shorter in dnNRSF myocytes in both experimental conditions (Figure 1E).

\section{Reduction of the Inward-Rectifier $\mathrm{K}^{+}$Current Density}

In ventricular myocytes, the RMP is primarily determined by the inward rectifier $\mathrm{K}^{+}$channel (IK1), close to the equilibrium potential of $\mathrm{K}^{+}(\mathrm{EK})$. In order to explore the ionic mechanisms underlying the reduced RMP in dnNRSF myocytes, we first measured the amplitude of IK1. In the experiments shown in Figures 2A, B, the membrane current was recorded using the ruptured whole-cell patch method and low- $\mathrm{Ca}^{2+}$ pipette solution. The family of current traces was activated by hyperpolarizing pulses from the holding potential of $-40 \mathrm{mV}$, in the presence and absence of $1 \mathrm{mmol} / \mathrm{L} \mathrm{BaCl}$. The amplitude of IK1 was defined as the $\mathrm{Ba}^{2+}$-sensitive current. In dnNRSF myocytes, the hyperpolarization-activated cation current ( $\mathrm{Ih}$ ) was consistently disclosed in the presence of $\mathrm{Ba}^{2+}$ (Figure 2B-b). Upon depolarization to $0 \mathrm{mV}$, the amplitude of the transient outward current ( $\mathrm{I}_{\mathrm{to}}$ ) appeared greater than that of the WT.

As is evident from the current-voltage (IV) relationship shown in Figure 2E-a, the amplitude of Iк1 was significantly smaller in dnNRSF myocytes. Furthermore, the cellular capacitance was significantly larger in dnNRSF myocytes (Figure 2C). As a consequence, the density of IK1 was remarkably reduced in dnNRSF myocytes; the density of the inward IK1 at $-140 \mathrm{mV}$ was $56.0 \%$ and the density of the outward Iк1 at $-60 \mathrm{mV}$ was $55.1 \%$ of WT myocytes, showing no voltage dependence in the inhibition (Figure 2E-b). The magnitude of the reduction of Ik1 density appeared to be in good agreement with the reduction of $\mathrm{dV} / \mathrm{dt}$ measured at $-60 \mathrm{mV}$. In cardiac myocytes, Kir2.1 is a major molecular component of the Iк1 channel, so we compared the amount of Kir2.1 mRNA using qPCR. However, there was no significant difference in the expression level of Kir2.1 (Figure 2D), which suggests that the reduction in IK1 density was caused by post-transcriptional mechanisms.

Transient Outward Current It has been reported that the voltage-gated outward currents, including Ito, play a major role in the modification of AP morphology in mouse cardiac myocytes. ${ }^{14}$ We compared the voltage-gated outward currents recorded in WT- and dnNRSF myocytes (Figure 3). In this experiment, the membrane current was activated from the holding potential of $-90 \mathrm{mV}$ in the physiological bathing solution. Therefore, robust activation of $\mathrm{Na}^{+}$current $(\mathrm{INa})$
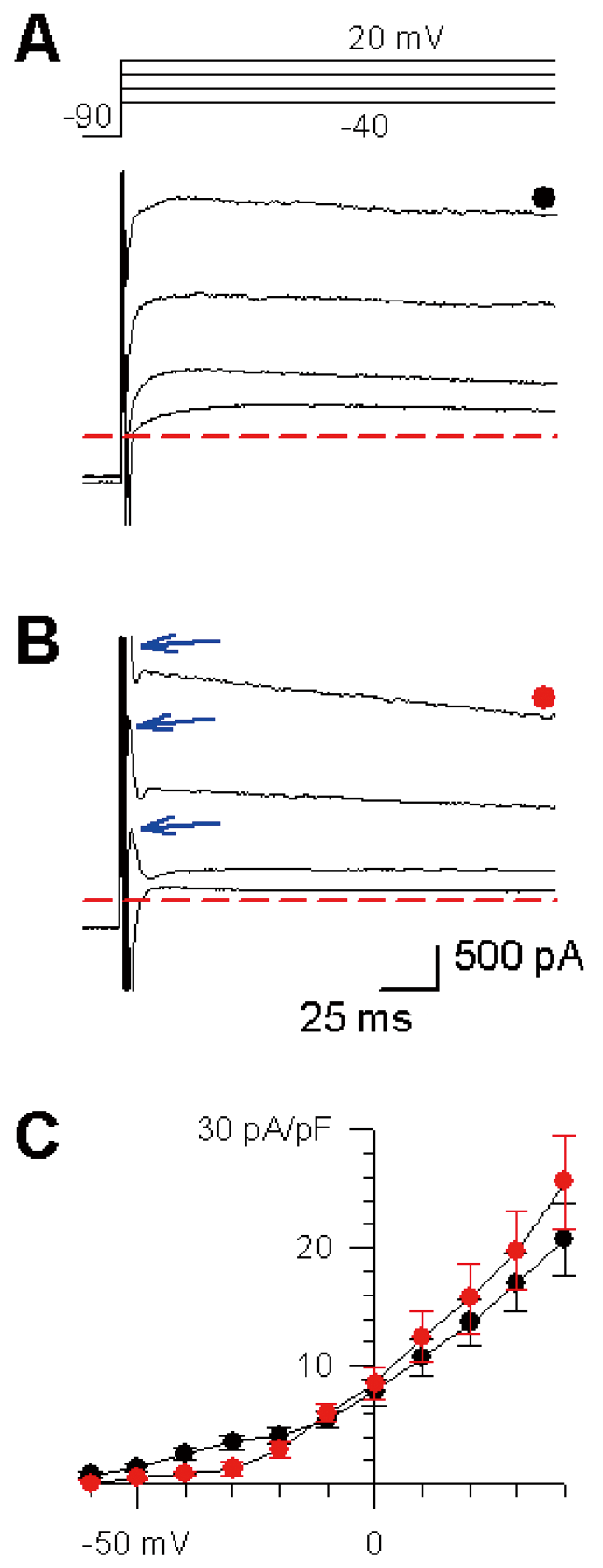

Figure 3. Comparison of the transient outward current (Ito) in wild-type (WT) and dnNRSF myocytes. (A) The family of current traces of lto recorded in a WT myoycyte. The pulse protocol is shown at the top. Ito was recorded in physiological bathing solution. The red dashed line indicates the zero current level. The robust inward current at the onset of depolarization is the voltage-gated $\mathrm{Na}^{+}$current $\left(I_{\mathrm{Na}}\right)$. The black circle indicates the position of the measuring the quasisteady state amplitude of Ito. (B) Two components of Ito recorded in dnNRSF myocytes. The blue arrows indicate the rapidly inactivating lto, which was additionally activated at membrane potentials more positive than $-20 \mathrm{mV}$. The red circle indicates the same as in (A). (C) IV-relationship of quasi-steady state amplitude of Ito. The slowly inactivating lto was activated at the membrane potentials more positive than $-50 \mathrm{mV}$. WT, black symbols $(n=4)$. dnNRSF, red symbols $(n=4)$. The current density was not statistically different. dnNRSF, dominant negative mutant of the neuron restrictive silencing factor. 
A

WT<smiles>CCC(C)=C(C)C</smiles><smiles>CCCCC</smiles>

dnNRSF

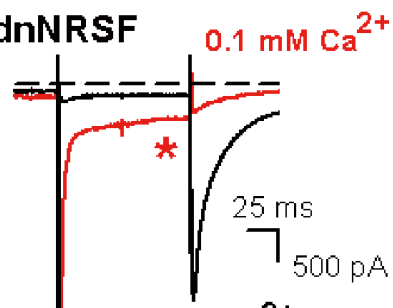

$1.8 \mathrm{mM} \mathrm{Ca}{ }^{2+}$

$-90$
B.

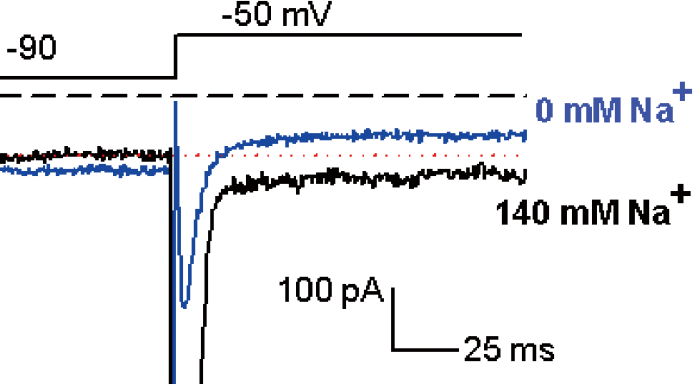

D

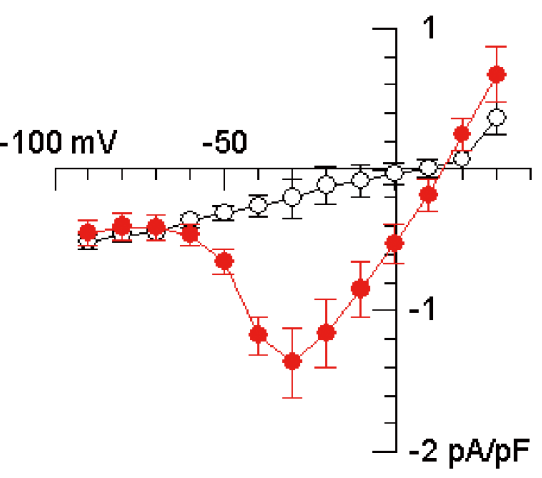

$\mathbf{E}$

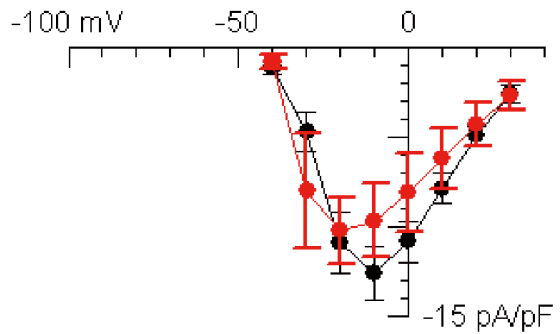

C

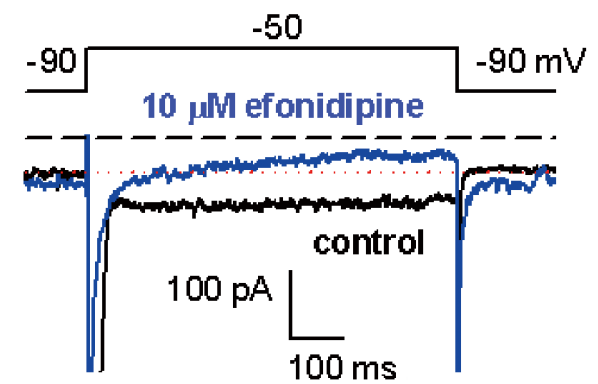

Figure 4. Na+-permeable, sustained inward current in dnNRSF myocytes. (A) Voltage-gated inward currents were activated by 2-step pulses. In the WT myocyte, no inward current was activated at $-50 \mathrm{mV}$. Ica-L was activated at $-10 \mathrm{mV}$. In the dnNRSF myocyte, late inward current was observed at the end of voltage stepping to $-50 \mathrm{mV}$. When the $\mathrm{Ca}^{2+}$ concentration of the bathing solution was reduced from $1.8 \mathrm{mmol} / \mathrm{L}$ (black lines) to $0.1 \mathrm{mmol} / \mathrm{L}$ (red lines), the amplitude of the late inward current was increased $(*)$. (B) $\mathrm{Na}^{+}-$sensitive nature of the late inward current activated at $-50 \mathrm{mV}$. The current traces were recorded in the presence (black line) and absence (blue line) of $140 \mathrm{mmol} / \mathrm{L} \mathrm{Na}$. The $\mathrm{Ca}^{2+}$ concentration was $1.8 \mathrm{mmol} / \mathrm{L}$. The dashed line indicates the zero current level, and the red dotted line is the mean holding current at $-90 \mathrm{mV}$. Note that late inward current was observed at $-50 \mathrm{mV}$ in the $140 \mathrm{mmol} / \mathrm{L} \mathrm{Na}$ bathing solution. In $\mathrm{Na}^{+}$-free conditions, Ica-T was disclosed at the onset of the voltage stepping at $-50 \mathrm{mV}$, whereas the late inward current was completely suppressed. (C) The late inward current activated by long voltage pulse $(500 \mathrm{~ms})$. The bathing solution contained $1.8 \mathrm{mmol} / \mathrm{L} \mathrm{Ca}^{2+}$ and $140 \mathrm{mmol} / \mathrm{L} \mathrm{Na}$. The dashed line and red dotted line indicate the same as in (B). $10 \mu \mathrm{mol} / \mathrm{L}$ efonidipine completely inhibited the late inward current. (D) IV-relationship of the late inward current. The current amplitudes were measured at the end of the 1st voltage pulse shown in the inset of $(\mathbf{A})$. Red symbols, $0.1 \mathrm{mmol} / \mathrm{L} \mathrm{Ca}^{2+} / 140 \mathrm{mmol} / \mathrm{L} \mathrm{Na}^{+}$. White symbols, $1.8 \mathrm{mmol} / \mathrm{L} \mathrm{Ca}^{2+} / 0 \mathrm{mmol} / \mathrm{L} \mathrm{Na}(\mathrm{n}=8)$. (E) IV-relationship of Ica-L. Red symbols, dnNRSF $(n=8)$; black symbols, WT $(n=8)$. The peak amplitude of lca-L was measured using the 2-step pulse protocol shown in (A). dnNRSF, dominant negative mutant of the neuron restrictive silencing factor; ICa-L, L-type $\mathrm{Ca}^{2+}$ current; WT, wild-type.

and L-type $\mathrm{Ca}^{2+}$ current (ICa-L) overlapped during the activation phase of the outward currents, and interfered with the measurement of the peak amplitude of Ito. We therefore compared the amplitudes of quasi-steady state currents of Ito. The densities of the quasi-steady state currents were not statistically different at any of the membrane potentials examined (Figure 3B).
However, at the onset of depolarization pulses, rapidly inactivating Ito was observed in dnNRSF myocytes at membrane potentials more positive than $-20 \mathrm{mV}$ (Figure 3B). The molecular entities of this rapid Ito remain unclear at present. An outward tail current of Ih may be partly involved. Because the time course of inactivation was extremely rapid, this component seemed completely inactivated at the quasi- 


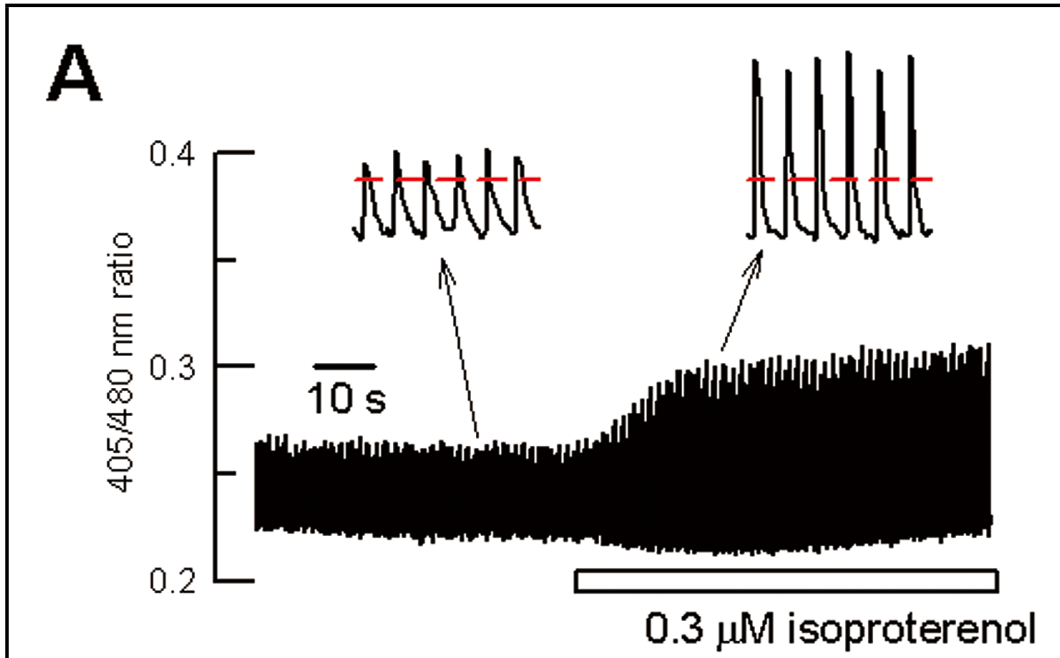

B

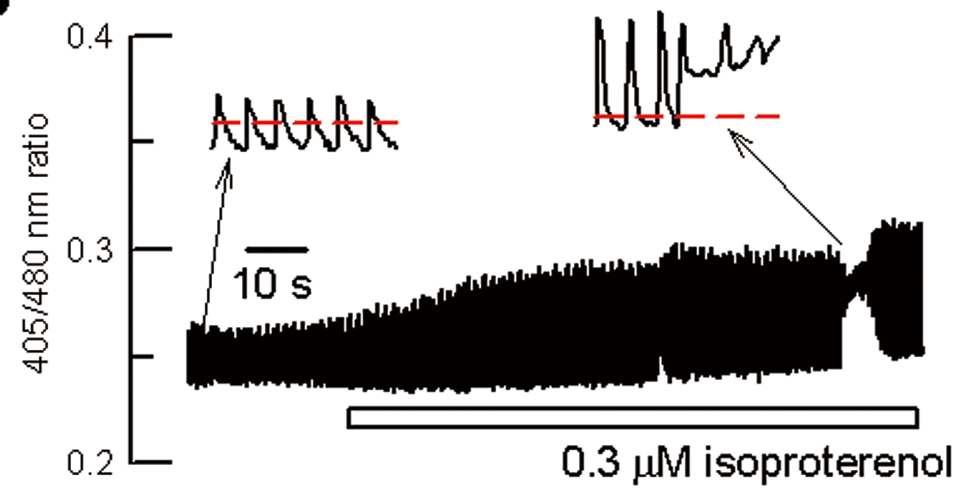

Figure 5. Intracellular $\mathrm{Ca}^{2+}$ transient measured with Indo-1AM. The abscissa indicates the ratio of fluorescent intensity measured at $405 \mathrm{~nm}$ and $480 \mathrm{~nm}\left(\mathrm{~F}_{405 / 480}\right)$. The Indo-1AM loaded myocytes were perfused with physiological bathing solution kept at $33-35^{\circ} \mathrm{C}$, and field-stimulated at $2 \mathrm{~Hz}$. (A) Continuous trace of $\mathrm{F}_{405 / 480}$ recorded in WT myocytes. The application of $0.3 \mu \mathrm{mol} / \mathrm{L}$ isoproterenol is indicated by the white bar. The inset shows the expanded traces of $\mathrm{F}_{405 / 480}$ for $3 \mathrm{~s}$, in the presence and absence of isoproterenol. The dashed line indicates $F_{405 / 480}=0.25$. (B) $F_{405 / 480}$ trace measured in dnNRSF myocytes. After the application of $0.3 \mu \mathrm{mol} / \mathrm{L}$ isoproterenol, diastolic $\mathrm{F}_{405 / 480}$ slightly increased, followed by spontaneous oscillation. The inset shows the expanded trace at the onset of spontaneous oscillation for $3 \mathrm{~s}$. The dashed line indicates $F_{405 / 480}=0.25$. (C) Summary of $F_{405 / 480}$ measured in WT and dnNRSF cardiac myocytes $(n=15, P<0.05)$. The black bars indicate diastolic $\mathrm{F}_{405 / 480}$, and the red bars, systolic $F_{405 / 480}$. In both the presence and absence of isoproterenol, diastolic $\mathrm{F}_{405 / 480}$ was significantly higher in dnNRSF $(n=15$, $P<0.05)$. dnNRSF, dominant negative mutant of the neuron restrictive silencing factor; WT, wild-type.

steady state in both WT and dnNRSF (Figures 3A, B). As shown in Figure 1, ADP@0mV was shorter in dnNRSF myocytes, presumably because the amplitude of the rapid Ito was larger in dnNRSF myocytes.

$\mathrm{Na}^{+}-$Permeable Late Current It has been reported that the late $\mathrm{Na}^{+}$current is increased in myocytes from a heart failure model. ${ }^{15,16}$ Therefore, we explored the possibility that $\mathrm{Na}^{+}$conductance might contribute to the reduced RMP in dnNRSF. In the experiments shown in Figure 4A, we activated the voltage-gated INa and ICa-L using 2-step voltage pulses. The $\mathrm{K}^{+}$conductance were completely suppressed by using a $\mathrm{Cs}^{+}$-rich pipette solution and by replacing extracellular $\mathrm{K}^{+}$with $\mathrm{Cs}^{+}$. In 8 of 40 myocytes isolated from dnNRSF, a sustained inward component was observed at the end of voltage stepping to $-50 \mathrm{mV}$. When the extracellular $\mathrm{Ca}^{2+}$ concentration was reduced from $1.8 \mathrm{mmol} / \mathrm{L}$ to $0.1 \mathrm{mmol} / \mathrm{L}$, the sustained inward component at $-50 \mathrm{mV}$ was clearly enlarged. However, such a sustained inward component was never recorded in WT myocytes.

In order to clarify the ionic selectivity of this component, dnNRSF myocytes were perfused with $\mathrm{Na}^{+}$-free, $1.8 \mathrm{mmol} / \mathrm{L}$ $\mathrm{Ca}^{2+}$ solution. As shown in Figure $4 \mathrm{~B}$, the inward current jump at $-50 \mathrm{mV}$ in $140 \mathrm{mmol} / \mathrm{L} \mathrm{Na}^{+}$solution was completely suppressed, and activation of the ICa-T followed by an outward current jump was disclosed. ICa-T was recorded in a small population of dnNRSF myocytes ( 5 of 75 ). Unexpect- 
edly, we found that this inward current jump at $-50 \mathrm{mV}$ was sensitive to calcium-channel blockers. As shown in Figure 4C, $10 \mu \mathrm{mol} / \mathrm{L}$ efonidipine almost completely inhibited the $\mathrm{Na}^{+}$-permeable, sustained inward current (Ist) at $-50 \mathrm{mV}$. Figure 4D shows the IV relationship of Ist measured at the end of the depolarizing pulse in $140 \mathrm{mmol} / \mathrm{L}$ $\mathrm{Na}^{+} / 0.1 \mathrm{mmol} / \mathrm{L} \mathrm{Ca}^{2+}$ solution, and in $\mathrm{Na}^{+}$-free $/ 0.1 \mathrm{mmol} / \mathrm{L}$ $\mathrm{Ca}^{2+}$ solution. Ist was activated at membrane potentials more positive than $-60 \mathrm{mV}$, and the reversal potential was between 10 and $20 \mathrm{mV}$.

The amplitude of ICa-L also affects the morphology of the AP of cardiac myocytes. We therefore compared the amplitude of ICa-L activated by a 2-step pulse protocol (Figure 4A). As is evident from the IV-relationship shown in Figure 4E, the density of ICa-L was not significantly different between WT and dnNRSF myocytes at any of the membrane potentials examined. However, the profile of the IV-relationship was slightly different: in WT myocytes, the peak of the IV relationship was at $-10 \mathrm{mV}$, whereas in dnNRSF myocytes, it was at $-20 \mathrm{mV}$.

\section{Intracellular $\mathrm{Ca}^{2+}$ Transient}

Alteration of intracellular $\mathrm{Ca}^{2+}$ handling as part of the remodeling in the hypertrophied or failing heart is well known. ${ }^{17}$ As shown in Figure 1, the EAD and prolonged APD observed in dnNRSF myocytes were completely suppressed by a specific blocker of the NCX. Therefore, it appears reasonable to expect that intracellular $\mathrm{Ca}^{2+}$ handling is also altered in dnNRSF myocytes. We compared the intracellular $\mathrm{Ca}^{2+}$ transient of intact myocytes isolated from WT and dnNRSF (Figure 5). The myocytes were loaded with Indo1$\mathrm{AM}$, and the ratio of fluorescent intensity was measured at $405 \mathrm{~nm}$ and $480 \mathrm{~nm}\left(\mathrm{~F}_{405 / 480}\right)$. The $\mathrm{Ca}^{2+}$ transient of myocytes was induced by field stimulation at $2 \mathrm{~Hz}$. As summarized in Figure 5C, diastolic F405/480 was $0.22 \pm 0.02$ in WT myocytes $(\mathrm{n}=15)$. In dnNRSF myocytes, the diastolic intracellular $\mathrm{Ca}^{2+}$ concentration $\left(\left[\mathrm{Ca}^{2+}\right]_{\mathrm{i}}\right)$ was significantly higher; F405/480 was $0.24 \pm 0.02(n=15)(P<0.05)$. In contrast, systolic $F_{405 / 480}$ was not significantly different between WT $(0.28 \pm 0.02, \mathrm{n}=15)$ and dnNRSF myocytes $(0.29 \pm 0.02, \mathrm{n}=15)$.

Adrenergic stimulation seemed to trigger abnormal electrical activity in dnNRSF myocytes, as reported previously. ${ }^{10}$ We therefore compared the effects of $0.3 \mu \mathrm{mol} / \mathrm{L}$ isoproterenol on the $\mathrm{Ca}^{2+}$ transient. As shown in Figure $\mathbf{5 A}$, the peak $\left[\mathrm{Ca}^{2+}\right]$ i of WT myocytes increased promptly after application of isoproterenol, and reached a steady level within approximately $40 \mathrm{~s}$. The diastolic $\left[\mathrm{Ca}^{2+}\right] \mathrm{i}$ decreased slightly but transiently from the control level. In dnNRSF myocytes, the systolic $\left[\mathrm{Ca}^{2+}\right] \mathrm{i}$ was also increased by isoproterenol, demonstrating that the response to $\beta$-adrenergic stimulation was retained. However, diastolic $\left[\mathrm{Ca}^{2+}\right]$ i slowly increased after the application of isoproterenol and spontaneous $\left[\mathrm{Ca}^{2+}\right]_{\mathrm{i}}$ oscillation was induced (Figure 5B inset). Spontaneous $\left[\mathrm{Ca}^{2+}\right]_{i}$ oscillation presumably activates the $\mathrm{Ca}^{2+}$-dependent inward current carried by the NCX, giving rise to the abnormal electrical activity of dnNRSF myocytes. ${ }^{10}$

In our experimental system, the maximal rate of image capture was 1 frame per $22 \mathrm{~ms}$. Because of this limitation, the recording of the $\mathrm{Ca}^{2+}$ transient was discontinuous; we could obtain only 22 data points with $22-\mathrm{ms}$ interval in 1 cycle $(500 \mathrm{~ms})$ of field stimulation. Therefore, it was practically difficult to evaluate the precise values of the time-topeak and the half relaxation time of the $\left[\mathrm{Ca}^{2+}\right]_{i}$ transient during the AP of mouse cardiac myocytes.

\section{Discussion}

In animal models of the hypertrophied or failing heart, physiological remodeling so far reported may be summarized as follows. First, alteration of intracellular $\mathrm{Ca}^{2+}$ handling, such as $\mathrm{Ca}^{2+}$ leak from the sarcoplasmic reticulum and downregulation of $\mathrm{Ca}^{2+}$-ATPase. Second, downregulation of the "repolarization reserve", such as decreased outward currents and/ or increased inward currents. Third, re-expression of fetaltype genes, such as contractile proteins and ion channels. ${ }^{1-4}$ Of these physiological remodeling processes, it has been suggested that transcriptional repressor REST/NRSF primarily plays a role in the regulation of fetal cardiac genes. In the heart, REST/NRSF represses the transcription of fetal cardiac genes in mature animals, and the hypertrophic stimulation appears to release, at least in part, the transcriptional repression by REST/NRSF. ${ }^{18}$

In the present study, we have demonstrated that inhibition of the REST/NRSF function significantly downregulated the "repolarization reverse" of ventricular myocytes, in addition to the re-expression of fetal-type ion channels such as $\mathrm{Ih}$ and ICa-T. The density of Iк1 was remarkably reduced, in spite of the mRNA level of Kir2.1 being unchanged. The mechanisms underlying the reduction in IK1 density is not clear at present. It has been reported that elevation of diastolic $\left[\mathrm{Ca}^{2+}\right]_{i}$ reduces IK1 density in rat hypertrophied myocytes, via protein kinase $\mathrm{C}(\mathrm{PKC})$-dependent and $\mathrm{PKC}$-independent pathways. ${ }^{19}$ Therefore, it might be speculated that in the hypertrophied heart a series of physiological changes (eg, reduction of IK1 density, depolarization of RMP, reduction of the driving force of NCX, elevation of diastolic $\left[\mathrm{Ca}^{2+}\right]_{i}$ ) could form a vicious spiral. Because diastolic $\left[\mathrm{Ca}^{2+}\right]$ i was also elevated in the dnNRSF myocytes (Figure 4), similar mechanisms might be involved in the reduction of IK1 density.

Ito is an important determinant of AP morphology in mouse cardiac myocytes, and a decrease in the Ito density should also reduce the "repolarization reserve". ${ }^{14}$ In the present study, the density of the slow component of Ito was not decreased in dnNRSF myocytes. In contrast, the density of rapidly inactivating $I_{t o}$ was increased. Because rapid Ito was only activated at membrane potentials $>-20 \mathrm{mV}$, and was completely inactivated within $5 \mathrm{~ms}$, this component might modify only the duration of overshoot, without affecting the duration of the plateau phase at $-40 \mathrm{mV}$. Vice versa, the activation of rapid Ito might increase the driving force of ICa-L, giving rise to a transient increase of $\mathrm{Ca}^{2+}$ influx.

As a mechanism of the reduction of the "repolarization reserve" and the generation of EAD in the hypertrophied heart, the late $\mathrm{INa}_{\mathrm{N}}$ is now receiving much attention. ${ }^{15,16}$ The late $\mathrm{I}_{\mathrm{Na}}\left(\mathrm{ie}\right.$, delayed inactivation of $\mathrm{I}_{\mathrm{Na}}$ ) seems to be regulated by calmodulin kinase II (CaMKII). ${ }^{20}$ In dnNRSF myocytes, it appears reasonable to expect that $\mathrm{INa}_{\mathrm{N}}$ was modified by CaMKII, which was activated by the elevation of diastolic $\left[\mathrm{Ca}^{2+}\right]$ i. In fact, the $\mathrm{Na}^{+}$-permeable, sustained $\mathrm{I}_{\text {st }}$ was observed in a small population of dnNRSF myocytes. Increase of $\mathrm{Na}^{+}$ influx through $\mathrm{Ist}_{\text {st }}$ and $\mathrm{I}_{\mathrm{h}}$ is anticipated in dnNRSF myocytes. Alteration of $\mathrm{Na}^{+}$homeostasis may reduce of the driving force of the NCX, thereby increasing $\left[\mathrm{Ca}^{2+}\right]_{\mathrm{i} .}{ }^{21}$

It has been reported that late $\mathrm{I}_{\mathrm{Na}}$ is sensitive to ranolazine. ${ }^{16}$ Although we have not yet examined the effect of ranolazine on Ist in dnNRSF myocytes, this current might not be delayed inactivation of INa, because Ist in dnNRSF myocytes was sensitive to calcium-channel blocker (Figure 3C), showing a similarity to the sustained inward current reported in the sino-atrial node. ${ }^{22}$ We have previously reported that 
efonidipine rescued the lethal arrhythmia of dnNRSF mice. ${ }^{10}$ Therefore, in addition to ICa-L and ICa-T, Ist might be an important pharmacological target in dnNRSF myocytes.

\section{Study Limitations}

It still remains unclear which of the primary genetic alternations caused by dnNRSF initiates the physiological remodeling series. Because diastolic $\left[\mathrm{Ca}^{2+}\right]$ i was elevated in dnNRSF myocytes, $\mathrm{Ca}^{2+}$-dependent genetic alterations might have subsequently occurred. ${ }^{23}$ It has been recently reported that Cav3.2 (Cacna1h) is required for cardiac hypertrophy induced by pressure overload. ${ }^{24}$ Likewise, crossbreeding of dnNRSF mice with transgenic mice lacking the target genes of REST/NRSF might provide a clue.

\section{Conclusion}

We found that RMP was reduced, and APD90 prolonged in dnNRSF myocytes. These changes were caused by a reduction in the "repolarization reserve", which in turn was caused by reduced IK1 density and the emergence of a $\mathrm{Na}^{+}$-permeable, late inward current. The diastolic $\left[\mathrm{Ca}^{2+}\right]_{i}$ was elevated, and spontaneous oscillation of $\left[\mathrm{Ca}^{2+}\right]$ i was induced by $\beta$ adrenergic stimulation. Under these conditions, the amplitude of EAD generated by the inward NCX current might be increased, thereby increasing the vulnerability to ventricular arrhythmia.

\section{Acknowledgment}

We appreciate the contribution of Akiko Kuratomi in the early stage of this work, and thank Taisho Pharmaceutical Co Ltd for the generous gift of SEA0400. This work was supported by grants-in-aid for Scientific Research from the Ministry of Education, Culture, Sports, Science and Technology of Japan (\#16650088, \#17659063), and the Vehicle Racing Commemorative Foundation.

\section{References}

1. Nattel S, Khairy P, Schram G. Arrhythmogenic ionic remodeling: Adaptive response with maladaptive consequences. Trends Cardiovasc Med 2001; 11: 295-301.

2. Tomaselli GF, Zipes DP. What causes sudden death in heart failure? Circ Res 2004; 95: 754-763.

3. Pogwizd SM, Bers DM. Cellular basis of triggered arrhythmias in heart failure. Trends Cardiovasc Med 2004; 14: 61-66.

4. Koyama T, Ono K, Watanabe H, Ohba T, Murakami M, Iino K, et al. Molecular and electrical remodeling of $\mathrm{L}$ - and T-type $\mathrm{Ca}^{2+}$ channels in rat atrium with monocrotaline-induced pulmonary hypertension. Circ J 2009; 73: 256-263.

5. Kuwahara K, Saito Y, Ogawa E, Takahashi N, Nakagawa Y, Naruse Y, et al. The neuron-restrictive silencer element-neuronrestrictive silencer factor system regulates basal and endothelin 1inducible atrial natriuretic peptide gene expression in ventricular myocytes. Mol Cell Biol 2001; 21: 2085-2097.

6. Kuratomi S, Kuratomi A, Kuwabara K, Ishii TM, Nakao K, Saito $\mathrm{Y}$, et al. NRSF regulates the developmental and hypertrophic changes of HCN4 transcription in rat cardiac myocytes. Biochem Biophys Res Commun 2007; 353: 67-73.

7. Kuwahara K, Saito Y, Takano M, Arai Y, Yasuno S, Nakagawa Y, et al. NRSF regulates the fetal cardiac gene program and maintains normal cardiac structure and function. EMBO J 2003; 22: 63106321.

8. Ohba T, Watanabe H, Takahashi Y, Suzuki T, Miyoshi I, Nakayama $\mathrm{S}$, et al. Regulatory role of neuron-restrictive silencing factor in expression of TRPC1. Biochem Biophys Res Commun 2006; 351: $764-770$.

9. Watanabe H, Murakami M, Ohba T, Ono K, Ito H. The pathological role of transient receptor potential channels in heart disease. Circ J 2009; 73: 419-427.

10. Kinoshita H, Kuwahara K, Takano M, Arai Y, Kuwabara Y, Yasuno $\mathrm{S}$, et al. T-type $\mathrm{Ca}^{2+}$ channel blockade prevents sudden death in mice with heart failure. Circulation 2009; 120: 743-752.

11. Shioya T. A simple technique for isolating healthy heart cells from mouse models. J Physiol Sci 2007; 57: 327-335.

12. Tanaka H, Namekawa I, Takeda K, Kazama A, Shimizu Y, Moriwaki R, et al. Unique excitation-contraction characteristics of mouse myocardium as revealed by SEA0400, a specific inhibitor of $\mathrm{Na}^{+}-\mathrm{Ca}^{2+}$ exchanger. Naunyn-Schmiederbers's Arch Pharmacol 2005; 371: $526-534$

13. Nagy ZA, Toth A, Biliczki P, Acsai K, Banyasz T, Nanasi P, et al. Selective inhibition of sodium-calcium exchanger by SEA0400 decreases early and delayed after depolarization in canine heart. $\mathrm{Br}$ J Pharmacol 2004; 143: 827-831.

14. Odening KE, Nerbonne JM, Bode C, Zehender M, Brunner M. In vivo effect of a dominant negative Kv4.2 loss-of-function mutation eliminating Ito,f on atrial refratoriness and atrial fibrillation in mice. Circ J 2009; 73: 461 - 467.

15. Valdivia CR, Chu WW, Pu J, Foell JD, Haworth RA, Wolff MR, et al. Increased late sodium current in myocytes from a canine heart failure model and from failing human heart. J Mol Cell Cardiol 2005; 38: 475-483.

16. Eckhardt LL, Teelin TC, January CT. Is ranolazine an antiarrhythmic drug? Am J Physiol 2008; 294: H1989-H1991.

17. Eisner DA, Kshimura T, Venetucci LA, Trafford AW. From the ryanodine receptor to cardiac arrhythmias. Circ J 2009; 73: 1561 1567.

18. Nakagawa Y, Kuwahara K, Harada M, Takahashi N, Yasuno S, Adachi Y, et al. Class II HDACs mediate CaMK-dependent signaling to NRSF in ventricular myocytes. J Mol Cell Cardiol 2006; 41: $1010-1022$

19. Fauconnier J, Lacampagne A, Rauzier JM, Vassort G, Richard S. $\mathrm{Ca}^{2+}$-dependent reduction of IK1 in rat ventricular cells: A novel paradigm for arrhythmia in heart failure? Cardiovasc Res 2005; 68: $204-212$

20. Xie LH, Chen F, Karaguenzian HS, Weiss JN. Oxidative stress induced afterdepolarizations and calmodulin kinase II signaling. Circ Res 2008; 104: 79-86.

21. Bers DM, Despa S. Cardiac myocytes $\mathrm{Ca}^{2+}$ and $\mathrm{Na}^{+}$regulation in normal and failing hearts. J Pharmacol Sci 2006; 100: 315-322.

22. Cho HS, Takano M, Noma A. The electrophysiological properties of spontaneously beating pacemaker cells isolated from mouse sinoatrial node. J Physiol 2003; 550: 169-180.

23. Heineke J, Molkentin JD. Regulation of cardiac hypertrophy by intracellular signaling pathways. Nat Rev Mol Cell Biol 2006; 7: 589-600.

24. Chiang CS, Huang CH, Chieng H, Chang YT, Chang D, Chen JJ, et al. The Cav3.2 T-type $\mathrm{Ca}^{2+}$ channel is required for pressure overload-induced cardiac hypertrophy in mice. Circ Res 2009; 104: $522-530$. 